\title{
Exploring Multiple Disciplines in Building Design Practice
}

\author{
Olaitan Awomolo
}

\begin{abstract}
While there are numerous benefits to working in teams comprising multiple disciplines, we do not have sufficient documented information on the functioning of multi-disciplinary teams in the building design context. As functioning impacts project outcomes, an understanding of the operation of building design teams comprising multiple disciplines is important.

To contribute to the body of knowledge that addresses this gap, this paper examines literature on disciplinary types and team performance. Using an analytic framework identified in literature, this paper studies the organizational and social aspects of building design practice in order to shed light on the ways in which the multiple disciplines involved building design work together. Findings presented in this paper suggest that building design teams combine and integrate knowledge, skills and capabilities in a multidisciplinary manner. In addition, this paper discusses four social and organizational characteristics of multidisciplinary building design teams - the project delivery approach, disciplinary roles, preexisting social and professional relationships, and location and geographic proximity - and documents their impacts on team functioning.
\end{abstract}

Keywords: building design teams, multidisciplinary teamwork, design process, integrated design teams

\subsection{Introduction}

Teams comprising multiple disciplines are necessary to solve real world problems as such problems often require knowledge from more than one discipline (Choi and Pak 2006, 351). For instance, the design of a building can be defined as a series difficult and multidimensional decisions that require knowledge from disciplines of architecture, engineering, planning, development, finance and others. These disciplines bring different skills and perspectives together to solving building design problems in a coordinated manner.
There are benefits and challenges of working in teams with multiple disciplines. Teams made up of multiple disciplines contribute to solution generation by providing different roles and perspectives that complement each other, far beyond the scope of a single individual or profession. Teams members are able to use the opportunities for informal learning that occur when different disciplines work together to improve the standard of team outcomes (Iliffe 2008; Pfeiffer 1981). However, boundaries between disciplines impose an artificial division of knowledge, presenting challenges to working with multiple disciplines. One challenge is a breakdown of

Stable URL: https://arcc-journal.org/index.php/arccjournal/article/view/455 10.17831/enq:arcc.v\%vi\%i.455

Corresponding Author: olaitan.awomolo@temple.edu

Published by the Architectural Research Centers Consortium under the terms of the Attribution-NonCommercial-ShareAlike 4.0 International license 
communication which may lead to conflict between team members and the poor integration of team processes.

Building designers are becoming increasingly aware of the benefits and challenges of working in multiple disciplines. One manifestation of this increased awareness of the potential benefits is Integrated Project Delivery (IPD), a project delivery approach that requires the early involvement of stakeholders from different disciplines to collaboratively solve problems and make decisions. In recognition of the challenges of working with multiple disciplines, building design firms are increasingly offering more than one specialization in-house. In their 2016 survey of firm profiles, the AIA found a decrease in architecture firms that describe themselves as singledisciplinary from about $60 \%$ to $50 \%$ from 2005 to 2015. Also, within this time, there was a corresponding $15 \%$ increase in architecture firms described as multidisciplinary or interdisciplinary (AIA 2006).

While we are increasingly aware of the complexities of working in multiple disciplines, there is a knowledge gap regarding the functioning of multiple disciplines in the building design domain. A vast amount of literature on teams with multiple disciplines exists in domains such as healthcare, manufacturing and software design, with very little from the building design domain. Although parallels can be drawn from studies in other domains, literature from these other domains does not accurately capture the complexities of building design. Consequently, we do not have sufficient documented information on the practices of building design teams. For example, we use the terms multidisciplinary and interdisciplinary interchangeably although they indicate different kinds of team functioning (Choi and Pak 2006; Kasali and Nersessian 2015). This inconsistent use of terminology clearly indicates that, in building design domain, there is a lack of attention on the ways in which our teams work.

To contribute to the body of knowledge that addresses this gap, this paper examines literature on disciplinary types, team performance and functioning. It reports on current building design team practice in order to understand the ways in which the multiple disciplines involved building design work together. The following section highlights six different disciplinary types found in literature that can occur in teams and suggests that the disciplines involved in building design function most like multidisciplinary teams. In order to examine multidisciplinary team functioning in building design, this paper reports on three cases of multidisciplinary building design teams. From the case studies, four social and organizational characteristics that impact the functioning of multidisciplinary building design teams are discussed - the project delivery approach, disciplinary types, preexisting social and professional relationships, location and geographic proximity.

\subsection{Disciplinary Organization and Building Design}

Boundaries between disciplines provide an artificial division of knowledge (Choi and Pak 2006). Real world problems rarely fit within a discipline and span multiple disciplines. The way in which the skills from these multiple disciplines are combined depends on the disciplinary types present within a team. Theoretical explorations have identified six ways that multiple disciplines in teams are organized ranging from single disciplinary teams - where all team members come from the same discipline - to transdisciplinary teams - where individuals assume roles outside their specific discipline (Garner 1994; Jantsch 1947).

While there is no common consensus in literature on the differences between disciplinary types, it is "widely accepted that the various disciplinary types described below are not synonymous with each other" (Lawrence 2010). Applying the right organizational lens to building design teams is important as team functioning impacts project outcomes - effective team functioning can mitigate project risk, reduce project waste and errors, and improve conflict resolution (McGraw-Hill 2014; Pinto and Pinto 1990; Love and Lopez 2012).

Single-discipline teams: The single discipline team is self-explanatory - all team members come from the same discipline. In the building design context, this would be a design team made solely of either architects, or one made up entirely of civil engineers. The nature and complexities of the building design process and systems that exist within buildings make it impossible for building design to occur in this way. This means single-discipline teams do not represent how the building design team functions. It is necessary to mention that as the building design process is fragmented; single-discipline sub-teams exist within the overall building design teams. 
Multidisciplinary teams: Jantsch describes the multidisciplinary team as consisting of a variety of disciplines working simultaneously, without explicitly defining the possible relationships and intersections between them. In building design, this means that the various disciplines work within their specific domain. Architects work on their spatial planning tasks without taking on the tasks of the civil or mechanical engineer. The disciplines on the team rely on coordination and communication to share knowledge and form a whole - building - solution (Jantsch 1947).

Pluridisciplinary teams: Pluridisciplinary teams have been described in different ways. Earlier research described them in terms of the hierarchy among disciplines. Based on this description, in the pluridisciplinary team, disciplines would be grouped in order to work together and share resources without needing to coordinate their tasks to form a single solution (Jantsch 1947; Piaget 1973). In building design, this would mean that the various disciplines share resources to work on their different problems without organizing their tasks and activities into a single building.

More recently, scholars have viewed pluridisciplinary teams in a very general sense, involving the presence of multiple disciplines on a team, rather than indicating a specific type of team functioning, further highlighting the lack of consensus on the definitions presented in literature (Hkilter 2015; Varaki and Babadi 2015).

Cross-disciplinary teams: Similar to pluridisciplinary teams, there are differences in the way crossdisciplinary teams have been defined in different fields. Early research in education viewed crossdisciplinary teams as consisting of one dominant discipline with other disciplines contributing to the work done by one main discipline (Fruchter 2001). However, research from other fields describes crossdisciplinary teams as teams that focus on work at the intersection of multiple disciplines, on things that are truly common among all the disciplines involved. Building design teams do not function in a crossdisciplinary manner as the different disciplines can often work in areas that diverge and do not only focus on the commonalities between their different areas.

Interdisciplinary team: In the interdisciplinary team, there is a shared or common language created by all the disciplines working together. There is "concerted action and integration of the disciplines towards achieving a shared goal" (Jantsch 1947). Interdisciplinary teamwork requires a shared conceptual framework, mental models and goals. By working together in this way, team members form a new combined discipline. An example would be the field of biomedical engineering, an interdisciplinary field which combines and integrates the disciplines of biology, medicine, engineering and healthcare.

Transdisciplinary team: Like the interdisciplinary team, team members in the transdisciplinary team have a shared framework within which they function. However, in the transdisciplinary team, individuals within disciplines come away from their disciplines and assume roles outside their specific discipline. The focus moves away from the disciplines to the knowledge and competencies that are used to solve problems within the complex and heterogenous domain they exist within (Lawrence 2010). Ramadier suggests that transdisciplinarity combines and goes beyond disciplinary processes, requiring a shift from disciplinary boundaries and divisions to a coherent and collaborative approach (Ramadier 2004).

These six disciplinary organization approaches indicate different types of functioning, hierarchies, coordination and integration of the contributions of multiple disciplines in teams. However, research in the areas of design, building design and architecture has focused on the terms interdisciplinary and multidisciplinary. Although these two indicate specific types of team functioning, they are used interchangeably in literature without accounting for the differences that the terms engender. Identifying and applying the right disciplinary type and context to building design team processes is a first step towards understanding and improving building design team practice. Table 1 highlights the difference between these two terms.

As described above, multidisciplinary teams are made of several separate disciplines working to achieve a common goal. Each discipline has their specific concepts, approaches and methods that are not shared or integrated with those of other disciplines. Team members bring a variety of knowledge from different disciplines, but work within individual disciplinary boundaries, while sharing information with each other. Knowledge is combined in an additive rather than integrative manner where the approaches and perspectives of different disciplines are combined without being changed (Bernard- 


\begin{tabular}{|c|c|c|}
\hline & Multidisciplinary Teams & Interdisciplinary, Integrated Teams \\
\hline Disciplines & $\begin{array}{l}\text { Involves working with several disciplines } \\
\text { Involves more than two disciplines }\end{array}$ & $\begin{array}{l}\text { Involves working between several disciplines } \\
\text { Involves reciprocity between two (or more) } \\
\text { disciplines }\end{array}$ \\
\hline Workflow & $\begin{array}{l}\text { Team members work in parallel or sequentially } \\
\text { on different aspects of a problem }\end{array}$ & $\begin{array}{l}\text { Team members work jointly on all aspects of the } \\
\text { problem }\end{array}$ \\
\hline Tasks & Tasks depend on individual disciplines & Tasks are shared regardless of disciplines \\
\hline Roles & $\begin{array}{l}\text { Team members have separate but related roles } \\
\text { and maintain disciplinary roles }\end{array}$ & Team members have common roles \\
\hline Boundaries & Disciplinary boundaries are maintained & Disciplinary boundaries are blurred \\
\hline Methods & Separate methods & Common methods \\
\hline Knowledge & $\begin{array}{l}\text { Complementary knowledge is used to address } \\
\text { problems and tasks through an additive process }\end{array}$ & $\begin{array}{l}\text { New knowledge and perspectives are created } \\
\text { through an integrative process }\end{array}$ \\
\hline Outcomes & The outcome is the sum of individual parts & $\begin{array}{l}\text { The outcome is more than the sum of individual } \\
\text { parts }\end{array}$ \\
\hline
\end{tabular}

Table 1. Multidisciplinary Teams versus Interdisciplinary Teams (Choi and Pak 2006)

Bonnin et al. 1995; Choi and Pak 2006; Derry, Schunn, and Gernsbacher 2014; Garner 1994; NSERC 2016).

Based on this definition, building design teams are multidisciplinary. Multidisciplinary building design teams are made up of several disciplinary stakeholders including architects, engineers, interior designers, urban planners and so on who work in parallel on different aspects of the overall building design problem with each discipline staying within their disciplinary boundary. In other words, architects do not solve the engineering problems, urban planners do not solve the interior designers' problems and so on. Each discipline has different approaches to solving their aspects of the problem. For example, engineers attempt to find an optimal engineering design solution while architects attempt to find the design solution that best satisfies the client requirements (Simon 1988).

When building design teams are called interdisciplinary, it suggests that the team works in a continuously integrated manner. This provides an inaccurate representation of current building design team practice. Interdisciplinary, integrated teams share ideas and fully integrate their different concepts, knowledge and methods, unifying links between them and forming a well-resolved whole solution. Each discipline's contribution is well interwoven such that individual contributions cannot be identified. Team members use frequent, collaborative exchanges to develop new knowledge beyond what is already known (Bernard-Bonnin et al. 1995; Choi and Pak, 2006; Garner, 1994; Grossman, 1979; NSERC, 2016).

Working in multidisciplinary teams poses a different set of challenges than working in interdisciplinary teams. These challenges primarily occur because multidisciplinary team members work within their individual disciplinary boundaries. Team members of one discipline can solve their individual problems without completely comprehending what other disciplines do. Overall, a lot of effort is required to coordinate between disciplines. This is not the case in interdisciplinary teams where frequent and collaborative exchanges are the norm and team members work together on most aspects of problem solving. An additional challenge stems from individual disciplines tending to have their individual language and jargon. Multidisciplinary teams are thus concerned with translating jargon and languages between disciplines which would not normally be an 
issue in an interdisciplinary team where team members have a shared language.

This distinction between multidisciplinary and interdisciplinary is important when studying building design teams as there are problems and challenges unique to each disciplinary type. Current building design team practice has been described as fragmented; team members are isolated from each other and information transfer between project stages can often improperly managed (IPCC 2007). This can lead to the development of silo culture in the building design team where team members work within their silos, delineated by their disciplinary boundaries, and are unable to function effectively across these boundaries (Bianca 2012).

Identifying and solving problems currently faced by building design teams depends on applying the accurate theoretical lens and terminology. Accounting for the differences between these two terms and applying the right one provides a clear description of building design teams without oversimplifying or misrepresenting how building design teams currently function.

\subsection{Framing an Inquiry into Multidisciplinary Building Design Practice}

Research on building design practice has primarily focused on understanding building design as a process. There are multiple accounts that outline the phases and steps required for building design (AIA 2006, 2017; BUILD LLC 2008; Designing Buildings 2017). Some of these studies have identified what tasks occur in the different stages of the building design process, the inputs and outputs of the tasks, and how the tasks connect with each other. Other studies have focused on the activities required for the different tasks involved in the design process.

However, such research has largely ignored the organization of building design and the broader social and economic factors that impact building design practice (Blau 1987). Few accounts have included descriptions of the building design team that identify the different professions on the team (Designing Buildings 2017; Lee 2015). These accounts do not include descriptions of the individuals making up the team, their knowledge, competencies and relationships.

This article concerns itself with the organization of building design practice, specifically the multidisciplinary teams involved in building design, the ways in which these teams combine their knowledge and abilities, as well as the broader factors that influence how these multidisciplinary building design teams work together. In order to do so, an analytical framework to guide the exploration of the organization of multidisciplinary building design teams is identified and described below.

\subsection{Analytical Framework}

In order to develop a complete understanding of how a team functions, it is necessary to obtain deep insights into what the team does, how the team does it and interrelations between team members. These insights can be obtained by identifying and describing four critical characteristics of teams: team context, multilevel team influences, team workflows, and team dynamics (Kozlowski and Bell 2003). These characteristics form a framework that can be used to describe and analyze the individuals, skills and interactions in the building design team.

Team context describes the environment and climate of a team that exists on two levels: proximal and distal. Proximal context includes the immediate environment of the team and can be described as the internal team environment. Distal context includes the broader external environment the team exists in (Bradbury and Kamey 2010). Descriptions of design team contexts would include rich descriptions from the perspectives of the different disciplinary team members, the relationships between them, and the larger organizations of which team members are a part.

Team context creates influences at different levels; these must be accounted for when studying teams. Multilevel influences include individual level characteristics, team level characteristics and the external characteristics that can affect how teams work (Cyert et al. 1963). In a building design team, identifying these influences involves analyzing the specific attributes at the individual, team, and external level, that influence team functioning and design outcomes.

Team workflows identify what teams do, their processes - how they convert inputs to outputs - and the structure within which team members carry out their responsibilities. Building design teams often have a structure or hierarchy that can be identified through team member roles and the activities they perform. This structure influences the interactions 
and links between team members, team processes and team effectiveness (Lichtenstein et al. 1997).

Finally, team dynamics reflect an understanding that teams constantly change over time. This characteristic is largely ignored in research, however, it is an essential characteristic as it relates activities to time; time has impacts on team learning and development (Kozlowski and Bell 2003). Since building design projects often have a short duration with team members who have been put together for specific purposes, it is easy to overlook the impacts of time. Identifying and describing changes that may occur contributes to the depth of information on team development and team functioning in building design.

These four team characteristics provide an analytical framework for studying the organization, functioning and characteristics of the multidisciplinary building design team. This framework was used to analyze and document three real-world cases of multidisciplinary building design teams, as described in the following section.

\subsection{Multidisciplinary Building Design Team Case Studies}

The analytic framework outlined earlier was applied to three cases of multidisciplinary building design teams. The cases, each comprising a multidisciplinary building design team, were identified based on the interest expressed by AEC firms contacted about participating in the study.

Data for the case studies was collected at different project stages. Data for Cases 1 and 3 was collected on completion of the design development stage of the project, while data for Case 2 was collected on completion of the schematic design stage, prior to the start of design development. Data was collected using in-depth interviews. In total, 32 team members across all the cases were interviewed. Ten team members were interviewed for Case 1 and Case 2 while twelve team members were interviewed for Case 3. The interview data was coded according the coding protocol - outlined in Table 2 - initially developed from the review of existing literature.

All the interview transcripts from the three cases were coded using this protocol. The coded data was analyzed by identifying the themes that emerged, first within each case, then across the three cases studied. It is necessary to mention that the findings discussed are specific to the cases studied. This paper does not aim to provide a global account of all building design teams, and the results described are not intended to be generalized to all building design practice. Rather, the paper aims to provide insights into building design team practice through the specific examples presented in the case studies

At the outset, it is necessary to discuss key case characteristics that influenced the results presented. Three main characteristics that described each case and provided contextual information for the findings are presented in Table 3: the team disciplines, project description, and challenges.

All the cases were made of members from at least six disciplines. Each team comprised architects, landscape architects, project managers, civil engineers, structural engineers, and mechanical/electrical/plumbing (MEP) engineers. The team in Case 1 was comprised of only these disciplines, while the teams in Cases 2 and 3 had additional disciplines to reflect the complexities of their individual projects. In addition to the six disciplines outlined earlier, the team in Case 2 also included construction managers, lighting designers, acoustic designers and audio-visual designers, and the team in Case 3 included construction managers, transportation engineers, sustainability consultants, and the commissioning agent.

The teams in all three cases worked on projects in Pittsburgh, PA. However, there were differences in the project types, sizes, and delivery approach. The team in Case 1 worked on the phase one development of a large, approximately 12.75-acre, campus-style, mixed-use redevelopment project. The project in Case 1 followed a traditional Design-BidBuild project delivery approach. As expected, in the case with the traditional approach, the owner held contracts with the architects for the design team and the contractors for the construction team. The teams in Case 2 and 3 both worked on institutional buildings. The building in Case 2 was 36,000sq ft., containing classrooms, collaborative workspaces, simulation spaces, office and conferencing spaces. The building in Case 3 was 40,000sq. ft., containing administrative spaces, collaborative workspaces, simulation spaces, office and conferencing spaces. The projects in Case 2 and 3 followed a CM at Risk project delivery approach. In the $\mathrm{CM}$ at Risk approach, the construction manager provided the owner with a guaranteed maximum price (GMP) contract and as 


\begin{tabular}{|c|c|c|c|c|}
\hline Codes & & Sub-Code & Definition & Example \\
\hline \multirow[t]{2}{*}{$\begin{array}{l}\text { Project } \\
\text { Characteristics } \\
\text { Context }\end{array}$} & \multirow[t]{2}{*}{-} & Description & $\begin{array}{l}\text { General information about the } \\
\text { project, specific project features } \\
\text { that differentiate it from others }\end{array}$ & $\begin{array}{l}\text { "That would be typically be how a } \\
\text { project of this type would be put } \\
\text { together" }\end{array}$ \\
\hline & & Challenges & $\begin{array}{l}\text { Project issues and concerns that } \\
\text { could not be controlled or } \\
\text { accounted for. }\end{array}$ & $\begin{array}{l}\text { "We actually switched contractors } \\
\text { which was very, very, disruptive to } \\
\text { the process" }\end{array}$ \\
\hline \multirow{8}{*}{\multicolumn{2}{|c|}{$\begin{array}{l}\text { Team } \\
\text { Characteristics } \\
\text { Workflows, } \\
\text { Influences }\end{array}$}} & Location & $\begin{array}{l}\text { The location of the different } \\
\text { disciplines with respect to each } \\
\text { other and the project }\end{array}$ & $\begin{array}{l}\text { "We want to be close to our } \\
\text { architectural clients, which is why } \\
\text { we are located..." }\end{array}$ \\
\hline & & Involvement & $\begin{array}{l}\text { Design stage when the different } \\
\text { disciplines were involved on the } \\
\text { project }\end{array}$ & $\begin{array}{l}\text { "Well in this instance we were } \\
\text { involved fairly early... so you know } \\
\text { very different stages of the } \\
\text { project..." }\end{array}$ \\
\hline & & Tasks & $\begin{array}{l}\text { The specific tasks and roles } \\
\text { performed by the different design } \\
\text { disciplines on the team }\end{array}$ & $\begin{array}{l}\text { "Sure, you know our responsibility is } \\
\text { to design the structure..." }\end{array}$ \\
\hline & & Relationships & $\begin{array}{l}\text { Prior working relationships and } \\
\text { personal relationships between } \\
\text { team members and the different } \\
\text { disciplines }\end{array}$ & $\begin{array}{l}\text { "Yes, so I've worked on this team } \\
\text { with on multiple projects" }\end{array}$ \\
\hline & & Organization & $\begin{array}{l}\text { Descriptions of the team structure } \\
\text { and hierarchy }\end{array}$ & $\begin{array}{l}\text { "So, we had myself, who could sort } \\
\text { of manage and be in parts of } \\
\text { different things," }\end{array}$ \\
\hline & & Social behavior & $\begin{array}{l}\text { Patterns of information exchange, } \\
\text { descriptions of interactions } \\
\text { between team members }\end{array}$ & $\begin{array}{l}\text { "There's a trust factor that's } \\
\text { developed. I think there's a, there's a } \\
\text { frankness and an honesty." }\end{array}$ \\
\hline & & Technology & $\begin{array}{l}\text { Tools and software that facilitated } \\
\text { the exchange of design } \\
\text { information }\end{array}$ & $\begin{array}{l}\text { "When you're able to take a model, } \\
\text { and spin it and see how the structure } \\
\text { interacts with the architecture..." }\end{array}$ \\
\hline & & Recommendations & $\begin{array}{l}\text { Descriptions of approaches to } \\
\text { ensure and improve effectible } \\
\text { communication } \\
\text { disciplines }\end{array}$ & $\begin{array}{l}\text { "quite often the model... is not... } \\
\text { their model isn't to the point where I } \\
\text { can figure things out. they say now... } \\
\text { oh you needed a dimension," }\end{array}$ \\
\hline
\end{tabular}

Table 2. Coding Protocol

such was involved with in the project from the start of design.

The teams in each case faced unique project challenges and design challenges. Project challenges were issues either external to, or beyond the control of the team such as a change in the project manager, while design challenges were a result of the project type and project complexity. The challenges provide the rationale for some of the findings discussed.

The team in Case 1 dealt with a change in the project manager in the middle of design development, and the need to reduce the project budget. These challenges were caused by changes in the vision and goals for the project, leading to a compressed time 


\begin{tabular}{|c|c|c|c|c|}
\hline \multicolumn{2}{|c|}{ Case Characteristics } & \multirow{2}{*}{$\begin{array}{l}\text { Case } 1 \\
6\end{array}$} & \multirow{2}{*}{$\begin{array}{l}\text { Case } 2 \\
10\end{array}$} & \multirow{2}{*}{$\begin{array}{l}\text { Case } 3 \\
10\end{array}$} \\
\hline $\begin{array}{l}\text { Team } \\
\text { Disciplines }\end{array}$ & $\begin{array}{l}\text { No. of } \\
\text { Disciplines }\end{array}$ & & & \\
\hline & Disciplines & $\begin{array}{l}\text { project managers, } \\
\text { architects, landscape } \\
\text { architects, civil engineers, } \\
\text { structural engineers, MEP } \\
\text { engineers }\end{array}$ & $\begin{array}{l}\text { project managers, } \\
\text { construction managers, } \\
\text { architects, } \\
\text { landscape architects, } \\
\text { civil engineers, } \\
\text { structural engineers, } \\
\text { MEP engineers, } \\
\text { lighting, acoustic, and AV } \\
\text { designers }\end{array}$ & $\begin{array}{l}\text { project \& construction } \\
\text { managers, architects, } \\
\text { landscape architects, civil } \\
\text { engineers, structural } \\
\text { engineers, MEP } \\
\text { engineers, transport } \\
\text { engineer, sustainability } \\
\text { consultant, } \\
\text { commissioning agent }\end{array}$ \\
\hline \multirow[t]{4}{*}{$\begin{array}{l}\text { Project } \\
\text { Description }\end{array}$} & Project Type & $\begin{array}{l}\text { Mixed use } \\
\text { redevelopment - } \\
\text { residential and } \\
\text { commercial }\end{array}$ & Institutional building & Institutional building \\
\hline & Project Size & - & 36.000 square feet & 40,000 square feet \\
\hline & Project Location & Pittsburgh, PA & Pittsburgh, PA & Pittsburgh, PA \\
\hline & $\begin{array}{l}\text { Delivery } \\
\text { Method }\end{array}$ & Design-Bid-Build & $\mathrm{CM}$ at risk & $\mathrm{CM}$ at risk \\
\hline \multirow[t]{2}{*}{ Challenges } & $\begin{array}{l}\text { Project } \\
\text { Challenges }\end{array}$ & $\begin{array}{l}\text { Change in the project } \\
\text { manager, the need to } \\
\text { reduce the project } \\
\text { budget }\end{array}$ & $\begin{array}{l}\text { Change in the project } \\
\text { scope and budget, } \\
\text { owner made of several } \\
\text { groups }\end{array}$ & $\begin{array}{l}\text { Project profile, } \\
\text { geographic separation of } \\
\text { team members, change in } \\
\text { the project manager, } \\
\text { aggressive design } \\
\text { schedule, owner made of } \\
\text { several groups }\end{array}$ \\
\hline & $\begin{array}{l}\text { Design } \\
\text { Challenges }\end{array}$ & - & $\begin{array}{l}\text { The maker space, } \\
\text { connections to existing } \\
\text { buildings }\end{array}$ & $\begin{array}{l}\text { New space types, transit } \\
\text { connections }\end{array}$ \\
\hline
\end{tabular}

Table 3. Case Characteristics

frame to develop the project delivery package. Also, challenges posed by the projects' size and scope meant the project was to be completed in four phases.

The team in Case 2 faced both project and design challenges. In Case 2, the project challenges included changes to the project scope and budget, and the large institutional owner made of several end user stakeholder groups with distinct requirements. Design challenges posed were the design of the makerspace, and connections to existing buildings. The makerspace - a large multi-story workshop/collaboration space - in particular presented several design challenges as it was a relatively new type of space with previously undefined requirements.

Along the same lines, the team in Case 3 also faced both project and design challenges. Project challenges were due to the high-profile nature the project, the location of the architect who was the design lead, and, again, the large co-owner group comprising many interested stakeholder groups. The project profile and scope meant there were significant master planning and neighborhood implications in addition to a change in the project manager, and an aggressive design schedule. As in Case 2, design challenges were the relatively new 
types of spaces - for instance the robot garden - with previously undefined requirements.

\subsection{Organizational and Social Factors Influencing Multidisciplinary Building Design Team Practice}

Findings from the case studies highlight relationships between a number of organizational and social characteristics of multidisciplinary building design teams and team functioning. This article discusses and documents the impacts of four social and organizational characteristics of multidisciplinary building design teams that emerged from the case study findings. These are preexisting social and professional relationships, location and geographic proximity, the project delivery approach, and disciplinary roles.

\section{A: Preexisting Social and Professional Relationships:}

Preexisting relationships are important in the multidisciplinary team - they form links across disciplines where there would typically be no links. On the multidisciplinary team, these links across disciplinary boundaries are extremely important as conflict can arise from a breakdown of communication which is more likely to occur across disciplinary boundaries when disciplines do not speak the same language or jargon. Preexisting social and professional relationships across disciplinary boundaries can minimize the impacts of conflict and positively contribute to team functioning and team outcomes.

In all three cases studied, for instance, there were preexisting social and professional relationships between the disciplines on the teams in the cases studied. These relationships were reported to be a contributing factor in firm selection and promoted positive team working environments. The preexisting relationships between disciplines modified the team contract structure as illustrated by the relationship between the civil engineers and the owner-developer in Case 1. The civil engineers reported that they had a preexisting professional relationship with the ownerdeveloper from working with them on a prior project:

"Actually, in this case, we knew the developer before the project. You know we worked with this developer in their other, in some of their other regions. So, when they were coming to look, some of our people introduced them to us and actually did some help with... sort of with the ground work..."
There was direct link between the civil engineers and the owner-developer owing to this prior relationship, where the owners held the contracts of the civil engineers. Without this relationship, the civil engineers would typically have been contracted to the architects.

The preexisting relationships between disciplines also determined the specific firms selected as the design sub-consultants. For instance, the civil engineers in Case 1 were aware that their prior relationship with the owner-developer contributed to them working on the project.

Case 2 provides another example of this finding where the project managers reported that in selecting the consultants to participate in their workshops, they only invited firms they had recently worked with or received proposals from:

"Some projects start out with like RFQs, Request for Qualifications. We send them out to those architectural firms and then they will send them back to us with their qualifications. This particular project though, we didn't go through the RFQs. We went to five architectural firms that we've done work with recently or we've seen proposals from them recently."

The quote shows that, in this case, the project managers had a clear preference for working with firms with whom they had preexisting relationships.

The main benefit of preexisting social and professional relationships was that they contributed to positive working relationships across disciplines. For instance, the architects in Case 1 reported that they had previously worked with the structural, civil and MEP engineers and had positive relationships with them:

"So, I had a lot of familiarity with the structural engineer, and the civil engineer. The firm had just... we are just wrapping up a project with the mechanical engineers. There are a lot of good working vibes and a positive working environment. The landscape architects, I haven't worked with them personally, but my firm has, maybe 15 to 20 times, and I know them personally, you know from the industry"

In other words, there was a positive working environment owing to the professional relationships between the disciplines, and even close social relationships between individual team members. 
The positive environment from preexisting relationships meant that disciplines could anticipate what each other would need even before the start of design, making them accountable to each other and leading to positive team outcomes. This could also address the communication challenges - potential issues of categorization and information silos - of multidisciplinary building design teams.

Existing research on familiarity and trust processes in teams supports these findings and suggest that the familiarity between team members promotes interpersonal attraction. Stronger interpersonal attraction leads to better team performance in several areas including the quality of their output, team satisfaction and cohesion (Harrison et al. 2003; Jehn and Shah 1997; Nooteboom and Six 2003).

Therefore, it makes sense that there would be a preference to work with familiar firms, since teams with familiar or recurring members outperform teams with unfamiliar members. This implies that trust and familiarity through preexisting relationships are necessary for positive multidisciplinary building design team functioning and outcomes.

However, there is one caveat with the benefits of relationships among disciplines and firms. It is possible to continually work with firms and disciplines to take advantage of the trust processes while overlooking others who may better suited to the project (by experience or capability). While this was not discussed in these cases, it is important to be aware of as relying on preexisting relationships may not be suited for all building design scenarios.

\section{B: Location and Geographic Proximity of Disciplines:}

The preexisting relationships between the disciplines in all the cases was in part due to the location of the disciplines. This suggests that by contributing to the development of preexisting relationships, the location and geographic proximity of the disciplines indirectly modifies the team's organization.

With the exception of Case 3, all the disciplines were located in the Pittsburgh area. The civil engineers in Case 1 described Pittsburgh as having a close-knit building design community:

"You know this is big small town and the civil engineering community, or the design...development community is...Very close-knit. Yeah. Everybody knows each other. You're in a room with a bunch of people which you've known for a long time. You know how they function a little better and just more comfortable, more relaxed, and lot easier to have a dialogue with somebody which you have history with."

In this close-knit building design community, design firms and consultants regularly work together on similar projects and develop social and professional relationships.

Having disciplines in a close-knit community where they can be co-located is ideal for multidisciplinary building design as positive social and professional relationships are likely to form. Research supports this finding where in their analysis of 145 software design teams, Hoegl and Prosperpio found that the degree of team member physical proximity is significantly related to the quality of teamwork as close physical proximity facilitated social relationships and coordination between team members (Hoegl and Proserpio 2004).

However, in Case 3, all disciplines were not located in Pittsburgh. Team members reported that this did not adversely affect design and only required increased coordination efforts between the disciplines.

In Case 3, the design architect - the design lead discipline - was located in a different city. From the findings in Cases 1 and 2, one would expect that having the lead discipline in a different location could adversely impact the team. Indeed, research on geographically dispersed teams suggests that when teams have distinct co-located subgroups comprising members in the same location (that is, subgroup $A$ in one location and subgroup B in another location), fault lines occur between the subgroups which leads to more conflict and less trust. This research also suggests that negative effects are worse in two subgroup teams with one fault line, than in three or more sub-group teams (Lau and Murnighan 2005; Polzer et al. 2006).

However, the location of the design architects as separate from the other design consultants did not negatively influence the perception of the team outcomes. As reported by the site civil engineers in Case 3, "I think it would've helped to have them here. But that's really for the ease of access to them and convenience. I don't think it created any undue stress or issues as a result of it...". While this difference in location was not ideal, it did not impact the disciplines perceptions of the team functioning or its outcomes. 
Research supports this finding from Case 3 and suggests that while geographic dispersion is not ideal, it does not necessarily present an issue for teams. Team members are able to combine their experiences by relying on the 'situated knowledge' of the subgroup more familiar with local practices (Sole and Edmondson 2002). Along these lines, team members in Case 3 specifically pointed to the close geographic proximity of most disciplines to the site as factor that address potential challenges of geographic dispersion. This proximity meant that they were familiar with regional practices and requirements and could anticipate expectations beforehand.

Based on these findings and as research expresses neither strong positive or negative impacts of location and geographic dispersion on teams, it is difficult to infer that the proximity of the different disciplines directly impacts multidisciplinary team practice. Rather, due to the nature and constraints on building design teams, this finding implies that co-location is ideal and contributes to preexisting relationships, and dispersion, while not ideal, is best dealt with familiarity to the project location and site.

Technology plays an important role in the functioning of geographically dispersed building design teams. Technology can be used to facilitate face-to face interactions between the different disciplines through video conferencing tools and share documents through file sharing and project management tools (in all fields, not just in building design). The use of video conferencing tools like WebEx and Skype for Business that allow screen sharing were described as being most useful to team member as they could point out issues and mark up drawings or models.

Findings suggest video conferencing with screen sharing eased the effects of having a remote lead discipline in Case 3. As reported by the structural engineers in Case 3: "I find that yeah, the further and further web conferencing technology progresses, it seems the less and less I'm actually really going into architect's offices."

Research which supports these findings suggests that geographically dispersed teams use virtual meeting tools which simulate the effects of working face to face (Gutierrez 2015). These tools allow team members in geographically dispersed teams exchange information in ways would not be possible, although - as with all technology - unexpected issues may arise which limit their use or functionality for team members (Hinds and Bailey 2003).

\section{C: The Project Delivery Approach:}

While it is expected that the project type of the building design team contributes to the specific disciplines, the team's organization and functioning that also contributes to the disciplines involved on the team is the project delivery approach. The specific

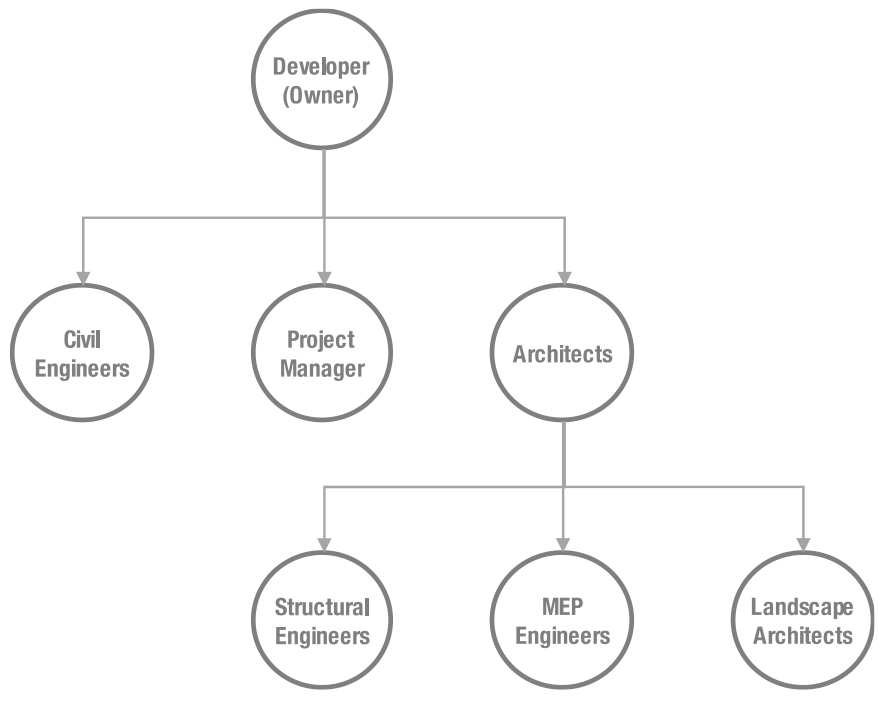

Figure 1. Organization of the Design-Bid-Build Project Team 
project delivery approach - Design-Bid-Build, DesignBuild, or $\mathrm{CM}$ at Risk - can influence not just the specific disciplines on the team but also the timing of involvement of the disciplines.

In the multidisciplinary team where team members work on different aspects of problem solving at different project stages, coordination and timing of involvement becomes an issue which would not be the case in an interdisciplinary, integrated team. As different project delivery approaches can have different involvement times for different disciplines, this suggests that the specific project delivery approach used by a building design team can influence its functioning.

A comparison of the disciplines and their organization in two project teams with different project delivery approaches, Design-Bid-Build and CM at Risk, illustrates this point.

The difference as shown in Figure 1 and Figure 2, comes from the involvement of the construction managers and other construction professionals during design in the $\mathrm{CM}$ at Risk project when compared with the Design-Bid-Build project. In this case, the construction managers were involved during design to ensure that the building design remained within the owners' budget, and the guaranteed maximum price (GMP) for construction.

The presence of the construction manager meant the project manager was central to the design team in the $\mathrm{CM}$ at Risk, rather than the architect in the DesignBid-Build. As the project managers held the contracts of the construction managers (and their subcontractors) and the architects (and their subconsultants), the project managers position became central to the team. Comparing both cases suggests that project managers become an influential figure in the organization of teams that use the CM at Risk project delivery approach, though this may not be the case in Design-Bid-Build projects.

The project managers in Case 3 reported that they preferred having the bulk of the disciplines on the design team - including the architects, design subconsultants, and the construction managers - present at the selection workshops that occurred during predesign:

"So, they presented to us and actually brought models in, so, they had time to think about how they would address this building. So, its kind of like, now we're not only looking at their fee, we are looking at - Hey, really how much do they really understand? And do they

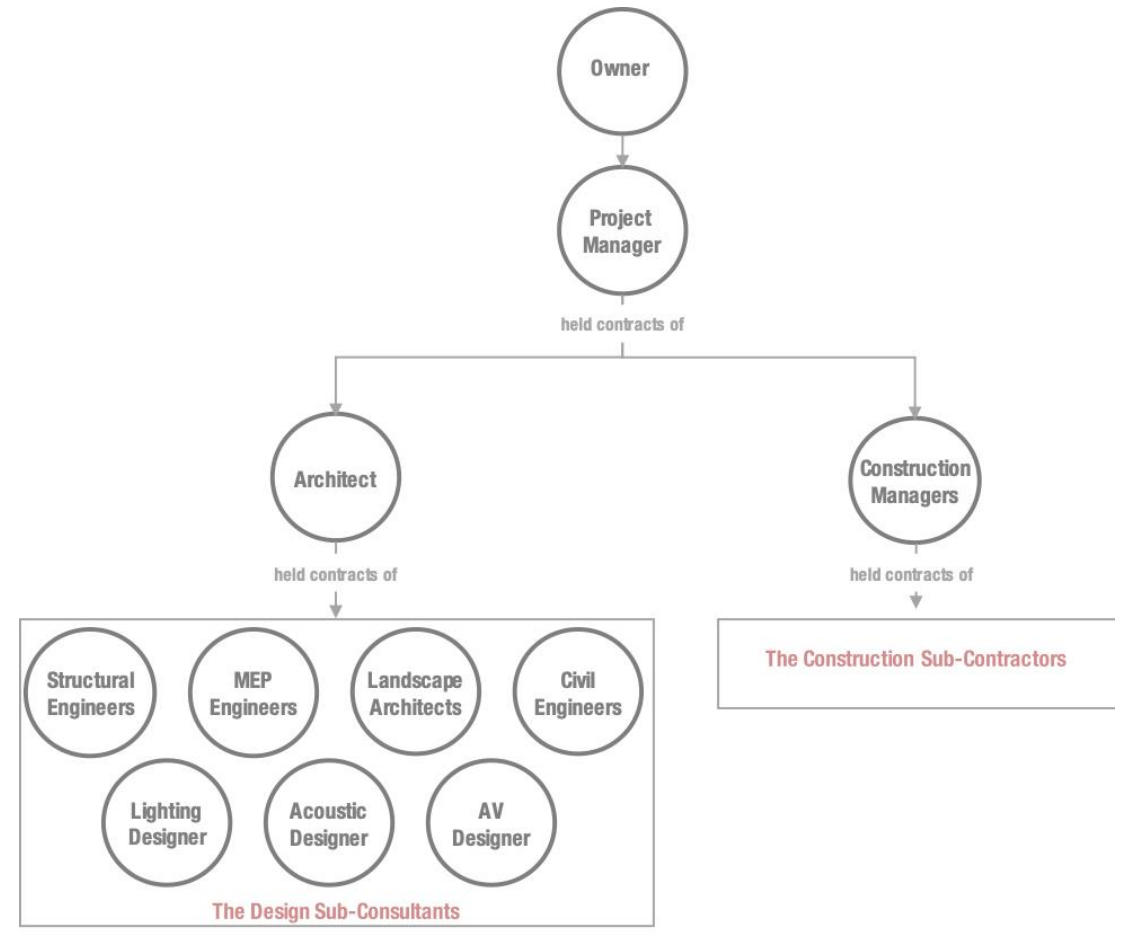

Figure 2. Organization of the $\mathrm{CM}$ at Risk Project Team 
understand the scope? Do they understand the difficulties of the site? And how do we like some of their solutions?"

Having all the disciplines involved this early was helpful as it provided the disciplines with clear goals for the project. and allowed the project managers to understand and assess each disciplines' response to the project goals and project challenges.

\section{D: Disciplinary Roles in the Multidisciplinary Team:}

Specific disciplines perform specific tasks in building design. For instance, while architects are responsible for the initial spatial design and layouts, it is the landscape architects and the civil engineers that work closely together on-site issues including surveying, site design, grading and so on.

Building design team members often perform roles that are separate from their specific disciplinary knowledge, such as certain team members acting as design team leaders on projects. Findings suggest that the roles that disciplines perform on the multidisciplinary team can influence overall team functioning and team practice. The different roles performed the project managers in the cases studied illustrates this finding.

Multidisciplinary teams require more efforts to coordinate different tasks and roles performed on the team and, as such, there is the need for a specific role as a coordinator. The project managers in the teams studied performed two distinct roles: that of crossfunctional connectors and that of project facilitators.
Cross-functional project managers are responsible for bridging the gaps between the disciplines on the team. This role differs from that of functional project managers, described either as disciplinary team leaders or team coordinators, who are responsible for coordinating and managing tasks and activities only within a specific discipline. The cross-functional project managers in the cases studied were responsible for connecting their discipline with all the other disciplines on the building design team. They did not perform design tasks or generate design information.

This differs from the project manager's role as team facilitators. Facilitation goes beyond the "command and control" of traditional project management and provides teams with the "support and framework" to work together successfully (Ellinger, Watkins, and Bostrom 1999). Rather than only make decisions and coordinate activities, project managers as facilitators are involved in guiding every step of the design process.

In the case where the project managers were facilitators, they served as the intermediary between the different disciplines on the team. They also connected the team with external stakeholders such as the owner, the user groups, planning and regulatory institutions. Building design facilitation, as described in the case studied, involves recognizing the needs and requirements of the various disciplines and stakeholders, and identifying and responding to the intersections between these needs and requirements at the whole project level. As facilitators, project managers represent and connect
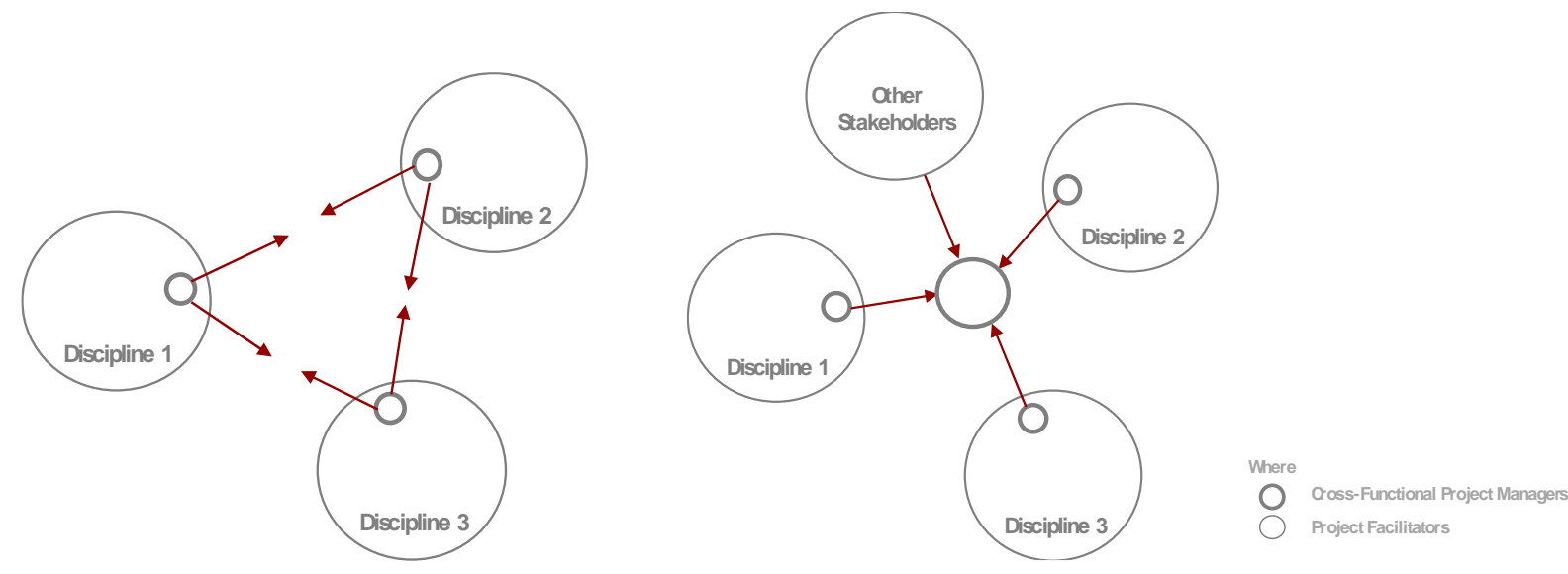

Figure 3. Cross Functional Project Managers vs Project Facilitators 
with all parts of the project rather than just representing a single disciplinary piece.

Both of the project manager roles, cross-functional connectors and team facilitators are beneficial to the functioning of the multidisciplinary building design team, as they contribute to team coordination efforts which can improve team performance and outcomes. It is worth mentioning that in addition to modifying the team organization, the project managers' role as facilitators can lead to improvements in team effectiveness and outcomes. Facilitation allows team members work together to learn from and be mutually accountable to each other (Patrick 2016). These benefits are achieved as team members are able to sit together, share ideas and ask questions to develop a mutual understanding of what they do, before beginning their design tasks.

\subsection{Conclusion}

Although we are increasingly aware of the benefits of working in teams comprising multiple disciplines, there is insufficient information on how these teams' function in the building design context. Consequently, we do not have sufficient documented information on the social and organizational practices and functioning of building design teams. To address this gap, research presented in this paper examined literature on team functioning and reported on three cases of current building design teams.

The terms multidisciplinary and interdisciplinary have been used interchangeably in both existing literature on building design and practitioners. This paper explored these terms to show that they function in different ways, each with their own strengths and challenges. Building design teams, as shown through the case studies, are multidisciplinary rather than interdisciplinary, although they may comprise subgroups that function in different ways. Clarifying these terms and clearly describing building design allows for accurate descriptions of practice that identify the issues and solutions specific to building design teams.

Multidisciplinary teams require more efforts to coordinate the different disciplines, tasks and roles performed on the team. The ways in which organizational and social factors influence the multidisciplinary building design team practice differs from how we expect them to impact other disciplinary types. For instance, with interdisciplinary, integrated team practice, we expect that the project delivery approach would have less influence on the involvement of disciplines on the team and contribute only to the organization of tasks on the team. Similarly, we expect distinct disciplinary roles to be de-emphasized, rather, team members will take on roles that involve providing support and guidance to the team. Pre-existing relationships and the location of the disciplines are not expected to greatly influence integrated team practice beyond promoting positive working relationships.

The focus on real-life teams means that the insights presented in this paper are applicable to actual building design practice. However, due to the contextual nature of the approach, there are a number of limitations to the research presented here including the number of cases studied and the use of self-reported data. It is unlikely (and not the intent) that the findings and results from the research are generalizable to all building design teams. The main strength of this approach which accounts for its lack of generalizability, is that the descriptions of the cases contribute to the knowledge base on building design teams and can be transferred to similar contexts (Bloomberg \& Volpe, 2008; Merriam \& Tisdell, 2015; Yin, 2013).

This article contributes to an increased understanding of the organization of multidisciplinary building design practice and raises several lines of inquiry for future research particularly with regards to: 1 ) what truly integrated, interdisciplinary practice would look like in the building design context and; 2) examining existing barriers to interdisciplinary building design practice. It is important to mention that achieving integrated practice is not expected to address all of the current challenges of building design practice, as interdisciplinary integrated team practice comes with its own challenges. However, integrated practice can go a long way in addressing some of the challenges of working in multidisciplinary teams, in particular ones due to fragmentation and silo culture, that affect building design practice today.

\section{Acknowledgements}

This article is developed from work done in doctoral research completed in 2017 at Carnegie Mellon University under the guidance of Omer Akin, Ramesh Krishnamurti, Molly Wright Steenson and Erica Cochran Hameen. 


\section{References}

AIA. 2006. "AIA Pittsburgh | Six Phases of Your Project." $2006 . \quad$ http://aiapgh.org/aiaarchitects/working-with-an-architect/six-phases-ofyour-project/.

- - - 2016. "Firm Survey Report: The Business of Architecture $2016 \quad$ - $\quad$ AIA." 2016. https://www.aia.org/resources/6151-firm-surveyreport-the-business-of-architectu.

- - - 2017. The Architecture Student's Handbook of Professional Practice. John Wiley \& Sons.

AIA California. 2008. "Integrated Project Delivery: Frequently Asked Questions." 2008. http://aiacc.org/wpcontent/uploads/2010/07/AIACC_1108FAQ.pdf.

Anderson, Brittany. 2016. "Facilitating Teamwork." SIGMA Assessment Systems (blog). November 29, 2016.

http://www.sigmaassessmentsystems.com/facilitati ng-teamwork/.

Babadi, Amin, and Bakhtiar Shabani Varaki. 2015 "Pluri-Disciplinary; Against the Common Perception of Collaboration Among Disciplines." Accessed July 2, 2019. https://www.academia.edu/11714139/PluriDisciplinary_Against_the_Common_Perception_of_C ollaboration_Among_Disciplines.

Bernard-Bonnin, Anne-Claude, Sylvie Stachenko, Diane Bonin, Christiane Charette, and Elisabeth Rousseau. 1995. "Self-Management Teaching Programs and Morbidity of Pediatric Asthma: A MetaAnalysis." Journal of Allergy and Clinical Immunology 95 (1): 34-41. https://doi.org/10.1016/s00916749(95)70150-8

Bianca, Audra. 2012. "What Do Silos Mean in Business Culture?" 2012.

http://yourbusiness.azcentral.com/silos-mean-

business-culture-3448.html.

Blau, Judith R. 1987. Architects and Firms: A Sociological Perspective on Architectural Practices. https://doi.org/10.2307/2392840

Bradbury, Thomas, and Benjamin Kamey. 2010. "Chapter 11: Stress and Social Support: Intimate Relationships in Context | Intimate Relationships: W. W. Norton 2010. http://www.wwnorton.com/college/psych/intimate- relationships/ch/11/summary.aspx. https://doi.org/10.1007/978-1-4899-3740-7 8

BUILD LLC. 2008. "The Process of Architecture | BUILD Blog." 2008. http://blog.buildllc.com/2008/09/theprocess-of-architecture/.

Choi, Bernard C. K., and Anita W. P. Pak. 2006. "Multidisciplinarity, Interdisciplinarity and Transdisciplinarity in Health Research, Services, Education and Policy: 1. Definitions, Objectives, and Evidence of Effectiveness." Clinical and Investigative Medicine. Medecine Clinique Et Experimentale 29 (6): 351-64.

Cyert, Richard M., James G. March, and others. 1963. "A Behavioral Theory of the Firm." Englewood Cliffs, NJ 2.

Derry, Sharon J., Christian D. Schunn, and Morton Ann Gernsbacher. 2014. Interdisciplinary Collaboration: An Emerging Cognitive Science. Psychology Press.

Designing Buildings. 2017. "Building Design Process Designing Buildings Wiki." 2017. https://www.designingbuildings.co.uk/wiki/Building _design_process.

Ellinger, Andrea D., Karen E. Watkins, and Robert P. Bostrom. 1999. "Managers as Facilitators of Learning in Learning Organizations." Human Resource Development Quarterly 10 (2): 105-125. https://doi.org/10.1002/hrdq.3920100203

Fruchter, Renate. 2001. "Dimensions of Teamwork Education." International Journal of Engineering Education 17 (4/5): 426-430.

Garner, H. G. 1994. "Multidisciplinary versus Interdisciplinary Teamwork." Teamwork in Human Services: Models and Applications across the Life Span, 19-36. https://doi.org/10.1016/b978-0-75069519-0.50007-6

Grossman, D. G. 1979. “A Quantitative System for the Assessment of Initial Organizational Needs in Transdisciplinary Research." Masteruppsats, the Faculty of the College of Natural Science Michigan State University.

Harrison, David A., Susan Mohammed, Joseph E. McGrath, Anna T. Florey, and Scott W. Vanderstoep. 2003. "Time Matters in Team Performance: Effects of Member Familiarity, Entrainment, and Task Discontinuity on Speed and Quality." Personnel 
Psychology; Durham 56 (3): 633-69. https://doi.org/10.1111/j.1744-

6570.2003.tb00753.x

Hinds, Pamela J., and Diane E. Bailey. 2003. "Out of Sight, Out of Sync: Understanding Conflict in Distributed Teams." Organization Science 14 (6): 61532. https://doi.org/10.1287/orsc.14.6.615.24872.

Hoegl, Martin, and Luigi Proserpio. 2004. "Team Member Proximity and Teamwork in Innovative Projects." Research Policy 33 (8): 1153-65. https://doi.org/10.1016/j.respol.2004.06.005.

Iliffe, Steve. 2008. "Myths and Realities in Multidisciplinary Team-Working." London Journal of Primary Care 1 (2): 100-102. https://doi.org/10.1080/17571472.2008.11493220

IPCC. 2007. Climate Change 2007 - Mitigation of Climate Change: Working Group III Contribution to the Fourth Assessment Report of the IPCC. Cambridge University Press.

Jantsch, Erich. 1947. "Inter- and Transdisciplinary University: A Systems Approach to Education and Innovation." Higher Education Quarterly 1 (1): 7-37. https://doi.org/10.1111/j.1468-

2273.1947.tb02067.x.

Jehn, Karen A., and Priti Pradhan Shah. 1997. "Interpersonal Relationships and Task Performance: An Examination of Mediating Processes in Friendship and Acquaintance Groups." Journal of Personality and Social Psychology 72 (4): 775-90. https://doi.org/10.5465/ambpp.1996.4980697

Kasali, Altug, and Nancy J. Nersessian. 2015. "Architects in Interdisciplinary Contexts: Representational Practices in Healthcare Design." Design Studies 41: 205-223. https://doi.org/10.1016/j.destud.2015.09.001

Kozlowski, Steve WJ, and Bradford S. Bell. 2003. "Work Groups and Teams in Organizations." Handbook of Psychology. http://onlinelibrary.wiley.com/doi/10.1002/0471264 385.wei1214/full.

Lau, Dora C., and J. Keith Murnighan. 2005. "Interactions within Groups and Subgroups: The Effects of Demographic Faultlines." Academy of Management Journal 48 (4): 645-659. https://doi.org/10.5465/amj.2005.17843943
Lee, Evelyn. 2015. "The Building Blocks for a Truly Multidisciplinary Practice." Contract Magazine. 2015. http://www.contractdesign.com/practice/businesspractice/The-Building-Blocks-for-a-TrulyMultidisciplinary-Practice-37124.shtml.

Lee, Sanghyun. 2001. "Challenges in Building Design and the Construction Industry: The Future of Design and Construction in the Internet Age." In The Human Society and the Internet Internet-Related SocioEconomic Issues, 225-36. Springer, Berlin, Heidelberg. https://doi.org/10.1007/3-540-477497_18.

Lichtenstein, Richard, Jeffrey A. Alexander, Kimberly Jinnett, and Esther Ullman. 1997. "Embedded Intergroup Relations in Interdisciplinary Teams Effects on Perceptions of Level of Team Integration." The Journal of Applied Behavioral Science 33 (4): 413434. https://doi.org/10.1177/0021886397334001

Nooteboom, B., and Frédérique Six. 2003. The Trust Process in Organizations: Empirical Studies of the Determinants and the Process of Trust Development. Edward Elgar Publishing. https://doi.org/10.1111/i.1468$\underline{0297.2004 .00258 \text { 12.x }}$

NSERC. 2016. "NSERC - Guidelines for the Preparation and Review of Applications in Interdisciplinary Research." June 28, 2016. http://www.nserccrsng.gc.ca/NSERC-CRSNG/Policies-

Politiques/prepInterdiscip-prepInterdiscip_eng.asp.

Patrick, Valerie. 2016. "The Benefits of Facilitation I IIFAC." Facilitation, Training and Coaching Services (blog). May 10, 2016. http://english.iifac.org/coffeebreak/the-benefits-of-facilitation/.

Pfeiffer, Steven I. 1981. "The Problems Facing Multidisciplinary Teams: As Perceived by Team Members." Psychology in the Schools 18 (3): 330$333 . \quad$ https://doi.org/10.1002/15206807(198107)18:3<330::aidpits2310180314>3.0.co;2-q

Piaget, Jean. 1973. Main Trends in Interdisciplinary Research. Harper \& Row New York. https://doi.org/10.1525/aa.1975.77.3.02a00260

Pinto, Mary Beth, and Jeffrey K. Pinto. 1990. “Project Team Communication and Cross-Functional Cooperation in New Program Development." Journal of Product Innovation Management 7 (3): 200-212. https://doi.org/10.1111/1540-5885.730200. 
Polzer, Jeffrey T., C. Brad Crisp, Sirkka L. Jarvenpaa, and Jerry W. Kim. 2006. "Extending the Faultline Model to Geographically Dispersed Teams: How Colocated Subgroups Can Impair Group Functioning." The Academy of Management Journal 49 (4): 679-92. https://doi.org/10.5465/amj.2006.22083024

Ramadier, Thierry. 2004. "Transdisciplinarity and Its Challenges: The Case of Urban Studies." Futures 36 (4):

423-439.

https://doi.org/10.1016/j.futures.2003.10.009

Shove, Elizabeth, Mika Pantzar, and Matt Watson. 2012. The Dynamics of Social Practice: Everyday Life and How It Changes. Sage publications.

Simon, Herbert A. 1988. "The Science of Design: Creating the Artificial." Design Issues, 67-82. https://doi.org/10.5040/9781474282932.0013

Sole, Deborah, and Amy Edmondson. 2002. "Situated Knowledge and Learning in Dispersed Teams." British Journal of Management 13 (S2): S17-34. https://doi.org/10.1111/1467-8551.13.s2.3.

Thomsen, Chuck, Joel Darrington, Dennis Dunne, and Will Lichtig. 2009. "Managing Integrated Project Delivery." Construction Management Association of America (CMAA), McLean, VA 105. http://danzpage.com/wpcontent/uploads/2009/06/Construction-

Management-

Resources_CMAA_White_Paper_Managing_IPD.pdf.

Valkenburg, Rianne, and Kees Dorst. 1998. "The Reflective Practice of Design Teams." Design Studies 19 (3): 249-271. https://doi.org/10.1016/s0142$\underline{694 \times(98) 00011-8}$

Yin, Robert K. 2013. Case Study Research: Design and Methods. 5 edition. Los Angeles: SAGE Publications, Inc. 